This item was submitted to Loughborough's Research Repository by the author.

Items in Figshare are protected by copyright, with all rights reserved, unless otherwise indicated.

\title{
Ultrasonically assisted drilling of rocks
}

PLEASE CITE THE PUBLISHED VERSION

https://doi.org/10.1063/1.5034699

\section{PUBLISHER}

AIP Publishing $($ The Authors

VERSION

AM (Accepted Manuscript)

\section{PUBLISHER STATEMENT}

This work is made available according to the conditions of the Creative Commons Attribution-NonCommercialNoDerivatives 4.0 International (CC BY-NC-ND 4.0) licence. Full details of this licence are available at: https://creativecommons.org/licenses/by-nc-nd/4.0/

\section{LICENCE}

CC BY-NC-ND 4.0

\section{REPOSITORY RECORD}

Mikhailova, N.V., P.Y. Onawumi, Anish Roy, and Vadim V. Silberschmidt. 2019. “Ultrasonically Assisted Drilling of Rocks". figshare. https://hdl.handle.net/2134/33938. 


\title{
Ultrasonically Assisted Drilling of Rocks
}

\author{
N.V. Mikhailova ${ }^{1, \text { a) }}$, P.Y. Onawumi², A. Roy ${ }^{2}$, V.V. Silberschmidt ${ }^{2}$ \\ ${ }^{1}$ Saint Petersburg State University, 7/9 Universitetskaya nab., St. Petersburg, 199034, Russia \\ ${ }^{2}$ Wolfson School of Mechanical, Electrical and Manufacturing Engineering, Loughborough University, Leicestershire, \\ LE11 3TU, UK \\ a) Corresponding author: natasha-mikh@yandex.ru
}

\begin{abstract}
Conventional drilling of rocks can generate significant damage in the drilled material; a material layer is often split off a back surface of a sample during drilling, negatively affecting its strength. To improve finish quality, ultrasonically assisted drilling (UAD) was employed in two rocks - sandstone and marble. Damage areas in both materials were reduced in UAD when compared to conventional drilling. Reductions in a thrust force and a torque reduction were observed only for UAD in marble; ultrasonic assistance in sandstone drilling did not result in improvements in this regard.
\end{abstract}

\section{INTRODUCTION}

Conventional drilling (CD) of brittle materials is one of the most common method of their machining. However, conventional drilling in rocks entails several challenges. Rocks are predisposed to cracking and splitting during drilling; as a result, large zones of drilling-induced damage are often observed in rocks especially at a drill-exit face.

In the last decades, ultrasonically assisted drilling (UAD) has been intensively applied to reduce the machininginduced damage and overcome problems facing $\mathrm{CD}$ [1]. This technique is based on ultrasonic vibration superimposed on tool movement or applied to a workpiece. A vibration direction can be vary; UAD in longitudinal and longitudinaltorsional directions are considered in [2]. It was claimed that the highest reduction of a thrust force (up to $45 \%$ ) was achieved in drilling with longitudinal-torsional vibrations.

Composites and metals are the most common materials considered in the research-related UAD. The technique showed significant improvement of drilling quality. UAD of carbon-fiber-reinforced plastics (CFRP) revealed decreasing - up to $60 \%$ - cutting forces and reduced ply delamination at a hole entry and exit [3]. Ultrasonic vibrations reduced a thrust force by $30 \%$ when drilling a CFRP laminate [4]. In [5,6] drilling of both CFRP and titanium alloys were studied. UAD resulted in a lower thrust force, tool wear and significantly reduced adhesion of titanium to a drill [5]. Analysis of temperatures in CFRP drilling is presented in [6].

UAD of metals resulted in thrust-force reduction and improvement of hole circularity and surface roughness [7,8]. Additionally, a comparative study revealed a chip-size reduction in UAD, which led to a higher tool life [9].

This work studies effects of applying ultrasonic vibrations in drilling of brittle materials. Experimental result for UAD and $\mathrm{CD}$ of sandstone and marble are presented. A comparison of both drilling techniques is provided.

\section{MATERIALS AND EXPERIMENTAL METHOD}

Here, two brittle materials are studied, namely, sandstone and marble. All samples were prepared in the form of flat plates with a thickness of approximately $1 \mathrm{~cm}$. Nominal material properties of these materials are listed in TABLE $\mathbf{1}$.

TABLE 1. Material properties

\begin{tabular}{llll}
\hline Property & Unit & Sandstone & Marble \\
\hline Density & $\mathrm{kg} / \mathrm{m}^{3}$ & 2579 & 2696 \\
Elastic modulus & $\mathrm{GPa}$ & 25.3 & 31 \\
Poisson ratio & - & 0.2 & 0.24 \\
Tensile strength & $\mathrm{MPa}$ & 13 & 4.5 \\
Fracture toughness & $\mathrm{MPa} \cdot \sqrt{\mathrm{m}}$ & 1.36 & 0.77 \\
\hline
\end{tabular}

An ultrasonically assisted drilling setup, available at Loughborough University, UK was used for the experimental studies. The drilling setup consists of a universal M-300 Harrison lathe modified to incorporate an ultrasonic transducer 
fixed in a lathe chuck acting as the tool holder. By operating the transducer, low-amplitude high-frequency vibration is imposed in the axial direction of a drilling tool thus changing a conventional drilling process into an ultrasonically assisted one [1]. To measure the levels of a thrust force and a torque during the drilling process, a Kistler two-component dynamometer was mounted on the cross-slide of the lathe. Further details of the setup used are available in [10].

For drilling marble and sandstone, a vibration frequency of $37 \mathrm{kHz}$ with an amplitude of $3.7 \mu \mathrm{m}$ was used during UAD. The drilling tool was Bosch CYL-5 masonry drill bit of $3 \mathrm{~mm}$ diameter manufactured to ISO 5468. All experiments were repeated two or three times for both drilling regimes.

\section{RESULTS AND DISCUSSION}

\section{Sandstone}

The sandstone samples used in our study had sufficiently homogeneous structure consisting of pressed sand/quartz. Thanks a high tensile strength and fracture toughness of sandstone in comparison to marble, higher magnitudes of forces and torques were recorded for it (Fig. 1). Interestingly, UAD led to somewhat higher force and torque signatures when compared to CD (usually, the opposite is observed). Nominally, they were less than $10 \%$ for the machining parameters studied; this difference reduced with an increase in the spindle speed (Fig. 2).
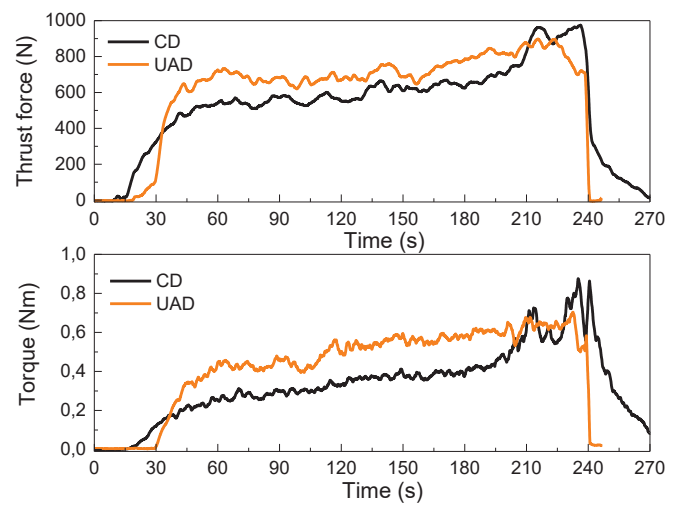

FIGURE 1. Thrust force and torque in CD and UAD of sandstone (spindle speed $40 \mathrm{rpm}$; and feed rate $0.1 \mathrm{~mm} / \mathrm{rev}$ ).

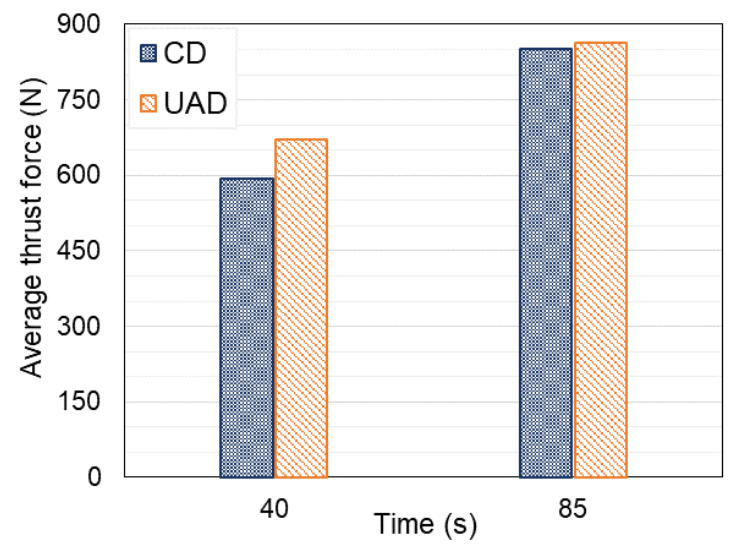

FIGURE 2. Average thrust force in UAD and CD of sandstone.

The ultimate goal of any drilling activity is to ensure good hole quality with reduced or negligible drilling-induced damage. An analysis of the exit hole surface obtained with CD and UAD revealed that UAD noticeably outperformed CD in this regard (Fig. 3). UAD reduced the damaged area around the drilled holes by an average of $36 \%$. This effect is probably due to the microchipping character, which is the primary mode of machining during UAD. Low-amplitude vibration induced localized damage in the vicinity of the cutting tool, thus reducing macroscopic splitting of the sandstone material. 


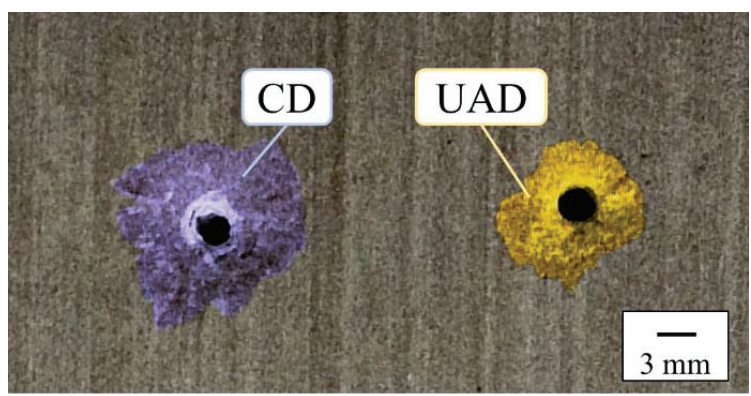

FIGURE 3. Damaged areas generated with $\mathrm{CD}$ and $\mathrm{UAD}$ in sandstone (exit surface).

\section{Marble}

Samples of white coarse-grained marble were tested with 7 different spindle speeds with a constant feed rate of 0.03 $\mathrm{mm} / \mathrm{rev}$. A grain size of more than $1 \mathrm{~mm}$ was apparent in the samples; as a result, the thrust-force and torque signatures had large variations (Fig. 4); so, the average thrust forces are reported. Here, UAD exerted lower thrust forces and torques in comparison to $\mathrm{CD}$. The averaged measured thrust forces for each spindle speed are presented in Fig. 5. Apparently, UAD shows force reduction of up to $53 \%$.

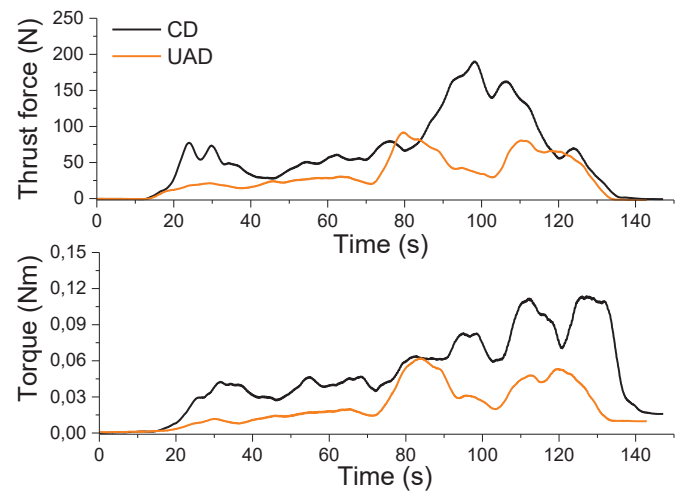

FIGURE 4. Thrust force and torque in CD and UAD of marble (spindle speed $180 \mathrm{rpm}$; feed rate $0.03 \mathrm{~mm} / \mathrm{rev}$ ).

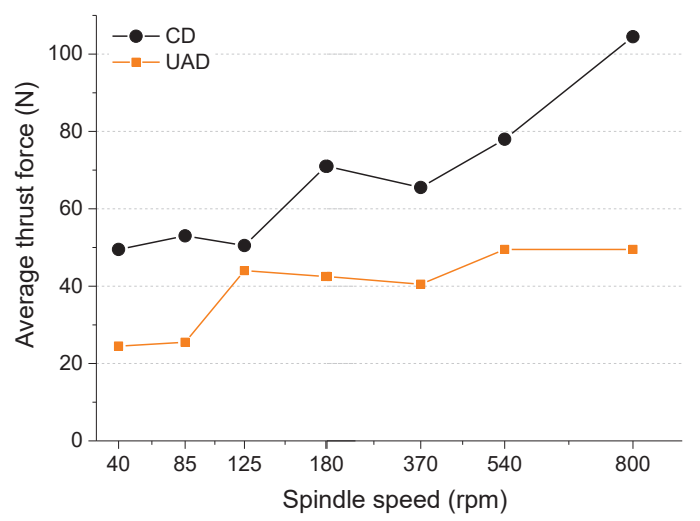

FIGURE 5. Average thrust force in $\mathrm{UAD}$ and $\mathrm{CD}$ of marble

The damaged areas of the material at drill exit were clearly visible on the polished marble surface; Figure 6 presents examples of two drill exits obtained with CD and UAD with spindle speed of $180 \mathrm{rpm}$ in the same specimen. In CD, the damaged area is considerably larger than for the hole drilled with ultrasonic assistance. To estimate the effect of ultrasonic vibrations, the areas of the damaged material around the drill holes were measured (TABLE 2). Significant improvements in hole quality was also observed for UAD. 


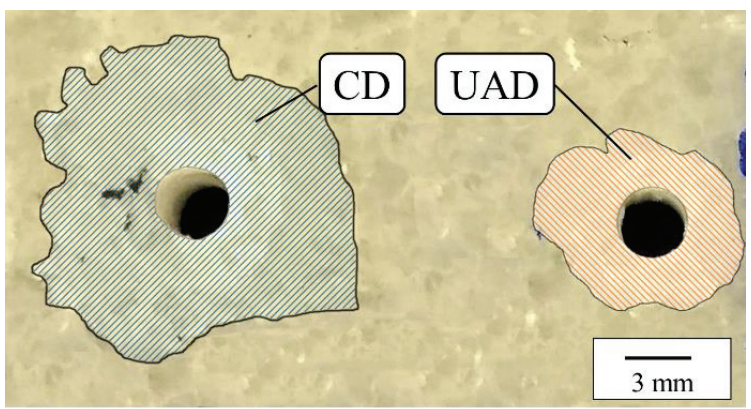

FIGURE 6. Damaged areas generated with $\mathrm{CD}$ and $\mathrm{UAD}$ in marble (exit surface).

TABLE 2. Averaged areas of damaged material measured on marble surface for different spindle speeds and for both drilling

\begin{tabular}{cccc}
\hline $\begin{array}{c}\text { Spindle speed } \\
\boldsymbol{r p m} \boldsymbol{m}\end{array}$ & $\begin{array}{c}\text { Average size of } \\
\text { damaged area in CD } \\
\mathrm{mm}^{2}\end{array}$ & $\begin{array}{c}\text { techniques. } \\
\text { Average size of } \\
\text { damaged area in UAD } \\
\mathrm{mm}^{2}\end{array}$ & $\begin{array}{c}\text { Reduction of } \\
\text { damaged area } \\
\text { \% }\end{array}$ \\
\hline 40 & 92.4 & 45.9 & 50 \\
85 & 103.4 & 54.4 & 47 \\
125 & 188.4 & 52.9 & 72 \\
180 & 165.9 & 44.9 & 73 \\
370 & 110.4 & 42.9 & 61 \\
540 & 143.4 & 43.9 & 69 \\
800 & 116.9 & 49.4 & 58 \\
\hline
\end{tabular}

\section{CONCLUSION}

Experimental studies in drilling of brittle rocks such as marble and sandstone using conventional and ultrasonically assisted drilling processes demonstrated the overall advantage of using UAD to achieve improved drill-hole quality. The micro-chipping process, causes by the intermittent character of tool-rock interaction in UAD led to reduced drill-exit damage. This is a preliminary study, showing the capability and potential advantage of hybrid machining processes such as UAD to replace conventional cutting processes, which are used in the industry. By tuning the vibration parameters (frequency and amplitude) and by customizing tools appropriate for UAD one is expected to improve significantly the results presented here. We expect to completely eliminate exit hole damage as was demonstrate in numerous UAD studies in brittle composites such as carbon/epoxy composites [10].

\section{ACKNOWLEDGMENTS}

This research was supported by the FP7 IRSES project TAMER IRSES-GA-2013-610547.

\section{REFERENCE}

1. P.N.H. Thomas and V.I. Babitsky, J. Sound Vib. 308, 815 (2007).

2. H. Paktinat and S. Amini, Int. J. Adv. Manuf. Technol. 37, 230 (2017).

3. F. Makhdum, L.T. Jennings, A. Roy, and V.V. Silberschmidt, J. Phys. Conf. Ser. 382, 012019 (2012).

4. V.A. Phadnis, F. Makhdum, A. Roy, and V.V. Silberschmidt, Procedia CIRP 1, 455 (2012).

5. A.N. Dahnel, H. Ascroft, and S. Barnes, Procedia CIRP 46, 420 (2016).

6. A. Sanda, I. Arriola, V. Garcia Navas, I. Bengoetxea, and O. Gonzalo, J. Manuf. Process. 22, 169 (2016).

7. B. Azarhoushang and J. Akbari, Int. J. Mach. Tools Manuf. 47, 1027 (2007).

8. H. Paktinat and S. Amini, Int. J. Adv. Manuf. Technol. 92, 2653 (2017).

9. Y.S. Liao, Y.C. Chen, and H.M. Lin, Int. J. Mach. Tools Manuf. 47, 1988 (2007).

10. F. Makhdum, V.A. Phadnis, A. Roy, and V.V. Silberschmidt, J. Sound Vib. 333, 5939 (2014). 